\title{
Incisional hernia repair
}

\author{
A. Bhattarai, R. S. Bhandari \\ Department of Surgery, Tribhuvan University Teaching Hospital, Kathmandu, Nepal
}

Correspondence to: abhishekbhattarai@gmail.com

\begin{abstract}
Introduction: Incisional hernia is a late complication of any abdominal surgery, including both laparotomy and laparoscopic. It occurs at the site of previous incision through weak scar. Hernia occurs as a result of excessive tension and inadequate healing of previous incision which is often associated with surgical site infection or severe bouts of coughing in the early post operative period or injury to the nerve supplying the abdominal wall. This study was performed with objectives to review clinical profile and management of incisional hernia in Tribhuvan University Teaching Hospital (TUTH).

Methods: Aretrospective study was conducted at TUTH, over the period of 18 month from, Jan 2007 to June 2008. All patients with a history of abdominal surgery with a complaint of swelling over previous incision site were included in this study.

Results: Twenty two patients who had undergone hernia repair during the period were included. Mean age of presentation was 47 years with the range of 27 to 80 year. Among them 17 were female and five were male. Among 17 female patients, 15 had history of laparotomy through lower midline incision and two had history of minilaparotomy for tubal ligation. Eleven patients had symptoms less than five years and 11 had more than five years. For 18 cases mesh repair was done while herniorraphy was performed in 4 cases. No complications were observed during one year follow up.

Conclusions: Incisional hernia is more common in females after lower midline abdominal surgery. Mesh repair is the ideal recommended treatment except in very small incisional hernia where primary repair can be done.
\end{abstract}

Keywords: Incisional hernia, laparotomy, mesh repair

\section{Introduction}

Incisional hernia, often referred to as ventral hernia, may occur in the area of any prior surgical incision. These hernias can vary in size from very small to very large and complex. Incisional hernias develop in up to $2-11.5 \%$ of surgical abdominal wounds usually after laparotomy $y^{1,2,3}$ These hernias most commonly develop as a result of disruption along or adjacent to the area of abdominal wall incision closure, tension placed on the tissue as a result of suturing and other inhibitors to adequate healing (infection, poor nutrition, long smoking history, obesity, or metabolic diseases).

These hernias present as a bulge or protrusion, at or near the area of the prior surgical incision scar. But most commonly occurring along mid-line incisions. ${ }^{2}$ These include those from major abdominal operation to small operations. Mid-line incisional hernias also have a higher rate of recurrence if repaired using a simple tissue-to-tissue or suture-only technique under tension and repair of large abdominal incisional hernias has a recurrence rate of up to $33 \%$ after first repair and $44 \%$ after second repair ${ }^{4}$ - mostly within 3 years of the repair. ${ }^{4,5}$ Therefore, it is advised that these hernias be repaired using a far more effective tension free repair method using mesh.

\section{Methods}

A retrospective study was conducted at TUTH, Kathmandu over a period of 18 month (January 2007 to June 2008). Data were collected from the hospital records and all patients who were clinically diagnosed and operated for incisional hernia were included in this study. 


\section{Results}

Total of 24 patients were admitted for operation. Two patients were excluded, leaving 22 for analysis. Among 22 patients,72.3\% $(n=17)$ were female (M:F ratio=1:3.4). Mean age of presentation was 47 years (range $=27-80$ years). Fifteen patients [68.18\%] were below the age of fifty where as seven were above it. Most of the female patients were below the age of fifty and male were above the age of fifty. Eleven patients (50\%) had duration of symptoms for less than 5 years. Lower midline incision scar was the major site of hernia $(72.3 \%, \mathrm{n}=16)$ and lower section caesarean section is the most common operation $(36.4 \%, n=8)$ followed by hysterectomy $(18.2 \%, n=4)$. None of them had history of laparoscopic surgery.

Table 1: Number of patients according to age

$\begin{array}{ll}\text { Age } & \text { No. of patients } \\ 20-29 & 1 \\ 30-39 & 6 \\ 40-49 & 8 \\ 50-59 & 3 \\ 60-69 & 3 \\ >70 & 1\end{array}$

Table 2: Previous operations

$\begin{array}{ll}\text { Previous operation } & \text { No. of patients } \\ \text { LSCS } & 8 \\ \text { Hysterectomy } & 4 \\ \text { Appendicular perforation } & 3 \\ \text { Minilap } & 2 \\ \text { Open cholecystectomy } & 2 \\ \text { Epigastric hernia } & 2 \\ \text { DU perforation } & 1\end{array}$

Chronic cough was the consistent factor present in cases of incisional hernia ( $41 \%, n=9$ ) (table 3 ) followed by wound infection in the early post operative period(32\%,n=7). Cigarette smoking, diabetes, alcohol, and chronic constipation were rest of the major associated factors with incisional hernias.

Table 3: Risk factors

$\begin{array}{ll}\text { Factors } & \text { No. of patients } \\ \text { Chronic cough } & 9 \\ \text { Wound infection } & 7 \\ \text { Smoking } & 6 \\ \text { Diabetes } & 5 \\ \text { Constipation } & 3 \\ \text { Alcohol } & 2\end{array}$

Mesh repair was done for 18 patients (82\%) and anatomical repair in 4 patients. Average duration of hospital stay was 3 days with range of two to five days. None of them developed complication during hospital stay.

All patients were followed up to see any recurrences and complication advised for regular follow up for recurrence, and development of any complication. None of them developed any complication or recurrence during one year of regular follow up.

\section{Discussion}

The midline incision is the preferred incision for surgery of the abdomen in emergency as well as elective procedure. The avascular nature of the linea alba minimises blood loss during the procedure. A supraumbilical midline incision is used for upper abdominal pathology and lower midline incision for lower abdomen, pelvic and gynecological pathology. In this incision, the damage to the segmental arteries and nerves is minimal ${ }^{6}$. However, evidence shows that transverse incision might reduce the chance of incisional hernia. ${ }^{7}$ Choice of suture, technique of closure, postoperative wound infection, mechanical stress due to increased intra-abdominal pressure caused by cough and abdominal distension are important predisposing factors to wound failure and subsequent development of incisional hernia. The surgical treatment of incisional hernia has changed rapidly during the last decade with the increasing use of mesh technique and the introduction of laparoscopy for hernia repair.

The incidence of incisional hernia is $2-11.5 \%$ following abdominal surgery. ${ }^{1,2,3}$, Incidence is increased if patient developed wound infection/burst abdomen, chronic cough during post operative period. In our study, most commonly associated predisposing factors were chronic cough, wound infection and diabetes.

Literature shows that incisional hernia is more common in females than in males. Our retrospective study also shows that incisional hernia is more common in female after lower midline incision. In this study most of the females were below the age of 50 and they were house wives suggesting early involvement in household activities with lax lower abdomen after delivery as a risk factor for developing incisional hernias.

Similar type of result was achieved by Faisal.GBbhopa.et.al who showed that true incidence of incisional hernia was $3.5 \%$ of all abdominal operations. Most of them had initial operations for gynaecological pathology and obstetrics purpose and Prolene mesh was used for all. ${ }^{8}$ 
In a study done by Halm et.al, two percent (1/60) of patients that had undergone the procedure through a transverse incision developed an incisional hernia as compared to $14 \%$ (9/63) of patients with midline incision group $(P=0.017){ }^{7}$ However, in our study most of the patients (82\%) had undergone midline incision for previous abdominal surgeries.

Incisional hernia rates do not differ by type of incision and incision should be driven by surgeon's preference with respect to the patient's disease and anatomy. ${ }^{9}$

The mesh repair is a simple and effective operation for incisional hernia. Ronald et al., in their study in 154 patients established the superiority of mesh repair over suture repair with regard to the recurrence of hernia. ${ }^{10}$ In our study, onlay repair technique was used and it appears to be safe in term of complication and recurrence rate. During our study we did not notice any major complications related to the use of this technique and there was no recurrence over the follow up period. The other advantage of this technique is little tissue dissection and easy access to the hernia repair.

\section{Conclusions}

Incisional hernia is more common in female after lower midline abdominal surgery. Post-operative wound infections, Diabetes, smoking, chronic cough are major contributing factors. Mesh repair is the ideal recommended treatment except in very small incisional hernia where primary repair can be done.

\section{References}

1. Guy Voller. Ventral abdominal hernia . Mastry of surgery 5th ed. 2007; vol 2.(2)

2. Bucknell TE, Cox PJ, Ellis H. Burst abdomen and incisional hernia: a prospective study of 1129 major laparotomies. BMJ 1982;284:931-3.

3. Mudge M, Hughes LE. Incisional hernia: a 10-year prospective study of incidence and attitudes. $\mathrm{Br} \mathrm{J}$ Surg 1985;72:70-1.

4. Langer S, Christiansen J. Long-term results after incisional hernia repair. Acta Chir Scand 1985; 151:217.

5. Read RC, Yoder G. Recent trends in the management of incisional herniation. Arch Surg 1989;124:485-8.

6. Nahai F, Brown RG, Vasconez LO. Blood supply to the abdominal wall as related to planning abdominal incisions. Am Surg 1976;42(9):691-5.
7. Halm JA, Schmitz HI, Jeekel J. Incisional hernia after upper abdominal surgery: a randomised controlled trial of midline versus transverse incision. Hernia 2009;3: 275-80.

8. Faisal GB, Ahmed M, Khan JS, Mehmood N, Y Azam, Iqbal M. Incisional hernia: aetiological factors and management 2000;6:5-12.

9. Seiler CM, Deckert A, Diener MK, Knaebel HP, Weigand MA, Victor N, et al. Midline versus transverse incision in major abdominal surgery: a randomized, double-blind equivalence trial. Ann Surg. 2009;249(6):913-20.

10. Lusijendrjk RW, Hop WC, van den To MP, de lange DC, Braaksma MM, Ijzermans JN, et al. A comparison of suture repair with mesh repair for incisional hernia, N Engl J Med. 2000 Aug 10;343(6):392-8. 